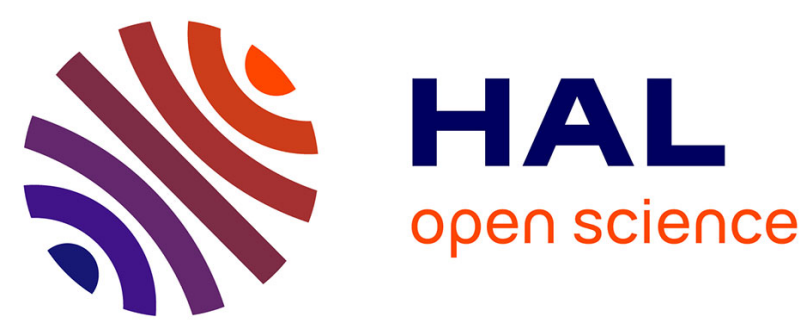

\title{
Changes of metabolism and functional connectivity in late-onset deafness: Evidence from cerebral 18 F-FDG-PET
}

\author{
Antoine Verger, Stephane Roman, Rose-May Chaudat, Olivier Félician, \\ Mathieu Ceccaldi, Mira Didic, Eric Guedj
}

\section{To cite this version:}

Antoine Verger, Stephane Roman, Rose-May Chaudat, Olivier Félician, Mathieu Ceccaldi, et al.. Changes of metabolism and functional connectivity in late-onset deafness: Evidence from cerebral 18 F-FDG-PET. Hearing Research, 2017, 353, pp.8-16. 10.1016/j.heares.2017.07.011 . hal-02479822

\section{HAL Id: hal-02479822 \\ https://hal.science/hal-02479822}

Submitted on 6 Apr 2020

HAL is a multi-disciplinary open access archive for the deposit and dissemination of scientific research documents, whether they are published or not. The documents may come from teaching and research institutions in France or abroad, or from public or private research centers.
L'archive ouverte pluridisciplinaire HAL, est destinée au dépôt et à la diffusion de documents scientifiques de niveau recherche, publiés ou non, émanant des établissements d'enseignement et de recherche français ou étrangers, des laboratoires publics ou privés. 


\section{Changes of metabolism and functional connectivity in late-onset deafness:}

\section{Evidence from cerebral ${ }^{18}$ F-FDG-PET}

Antoine Verger MD, $\mathrm{PhD}^{1,2,3}$, Stephane Roman MD, $\mathrm{PhD}^{4,6}$, Rose-May Chaudat, $\mathrm{MSci}^{5}$, Olivier Felician MD, $\mathrm{PhD}^{5,6}$, Mathieu Ceccaldi MD, $\mathrm{PhD}^{5,6}$, Mira Didic $\mathrm{MD}, \mathrm{PhD}^{5,6}$, Eric Guedj, $\mathrm{MD}, \mathrm{PhD}^{1,7,8}$.

${ }^{1}$ Department of Nuclear Medicine, Assistance Publique-Hôpitaux de Marseille, Aix-Marseille Université, Timone University Hospital, France;

2 Department of Nuclear Medicine \& Nancyclotep Imaging platform, CHRU Nancy, Lorraine University, France;

${ }^{3}$ IADI, INSERM, UMR 947, Lorraine University, Nancy, France;

${ }^{4}$ Department of Pediatric Otolaryngology and Neck Surgery, Assistance Publique-Hôpitaux de Marseille, Aix-Marseille Université, Timone University Hospital, France;

${ }^{5}$ Department of Neurology and Neuropsychology, Assistance Publique-Hôpitaux de Marseille, Aix-Marseille Université, Timone University Hospital, France;

${ }^{6}$ Aix Marseille Univ, INSERM, UMR 1106, INS, Institut de Neurosciences des Systèmes, Marseille, France;

${ }^{7}$ Aix Marseille Univ, CNRS, UMR 7289, INT, Institut de Neurosciences de la Timone, Marseille, France;

${ }^{8}$ CERIMED, Aix-Marseille Université, Marseille, France.

\section{Original Article}

Word count: 4264

\section{Address for correspondence:}

Eric Guedj, M.D., Ph.D.

eric.guedj@ap-hm.fr

Service Central de Biophysique et Médecine Nucléaire, Hôpital de la Timone, 264 rue Saint Pierre, 13005 Marseille, France.

Tel: +33-491385558; Fax: +33-491384769 
Hearing loss is known to impact brain function. The aim of this study was to characterize cerebral metabolic Positron Emission Tomography (PET) changes in elderly patients fulfilling criteria for cochlear implant and investigate the impact of hearing loss on functional connectivity. Statistical Parametric Mapping-T-scores-maps comparisons of ${ }^{18}$ F-FDG-PET of 27 elderly patients fulfilling criteria for cochlear implant for hearing loss (best-aided speech intelligibility lower or equal to $50 \%$ ) and 27 matched healthy subjects ( $<<0.005$, corrected for volume extent) were performed. Metabolic connectivity was evaluated through interregional correlation analysis. Patients were found to have decreased metabolism within the right associative auditory cortex, while increased metabolism was found in prefrontal areas, preand post-central areas, the cingulum and the left inferior parietal gyrus. The right associative auditory cortex was integrated into a network of increased metabolic connectivity that included pre- and post-central areas, the cingulum, the right inferior parietal gyrus, as well as the striatum on both sides. Metabolic values of the right associative auditory cortex and left inferior parietal gyrus were positively correlated with performance on neuropsychological test scores. These findings provide further insight into the reorganization of the connectome through sensory loss and compensatory mechanisms in elderly patients with severe hearing loss.

Key-words: cochlear implant; connectivity; deafness; elderly; ${ }^{18}$ F-FDG-PET 


\section{Introduction}

Hearing loss affects 40 to $50 \%$ of adults over the age of 65 and $83 \%$ of adults over the age of 70 (Cruickshanks et al., 1998). It is the third most prevalent chronic medical condition amongst elderly patients after arthritis and hypertension (Lethbridge-Cejku et al., 2004). Downstream consequences of reduced hearing include negative effects on perceptual effort for encoding of what has been heard (McCoy et al., 2005; Cousins et al., 2014) and increased resource demand for comprehension of sentences with complex syntax (Wingfield et al., 2006). This can lead to decreased performance on standardized cognitive tests (Lin et al., 2011a) and might explain an association with dementia (Gates et al., 2011; Lin et al., 2011b). Hearing loss, cognitive impairment and dementia can be thus intertwined, especially in elderly patients, with aging being a major risk factor for neurodegenerative disorders. However, the functional mechanisms that lead to cognitive dysfunction in these patients are poorly understood. Over the past decades, there has been extensive evidence for cortical reorganization following hearing loss in studies involving both experimental animals and humans (Irvine and Rajan, 1996; Rajan et al., 1993; Kang et al., 2003; Lee et al., 2003). Mechanisms of reorganization involve cross-modal plasticity, where deprivation in one sensory modality (e.g. the auditory modality in hearing loss) results in the recruitment of cortical resources of the deprived modality by intact sensory modalities (e.g. visual or somatosensory systems), as described in congenital but also post-lingual deafness (see (Glick and Sharma, 2017) for review). Moreover, in the auditory system, in addition to ascending auditory pathways that carry information on sound from the cochlea to auditory cortices, descending pathways from higher auditory centers project back towards the periphery. These "top-down mechanisms" are thought to play a compensatory role after peripheral deafferentation through descending projection systems, but how these networks are modulated 
precisely remains unknown (see (Lesicko and Llano, 2017) for review). Kral et al. recently conceptualized congenital auditory-loss like a "connectome disease" because of distal effects from the sensory system onto higher order neurocognitive functions (Kral et al., 2016), the connectome being defined as a map of neural connections in the brain (Sporns et al., 2005). Referring to hearing loss as a connectome disease is an opportunity to examine hypotheses concerning the effects of hearing loss on brain regions not directly involved in audition per se on the large-scale neural network scale, and also to identify potential targets for rehabilitation."

Cochlear implant (CI) is the only effective therapeutic method for patients suffering from profound sensorineural hearing loss (Ramos-Macías et al., 2016). Hearing loss has a significant impact on patients' social life, daily activities, and self-esteem (Ramos-Macías et al., 2016). In patients over the age of 65 , a comprehensive neurocognitive assessment is required before surgery in order to rule out a neurodegenerative condition, which could interfere with the ability of patients to adapt to CI (see guidelines provided by the French National Authority for Health or Haute Autorité de Santé, HAS, France, HAS santé, 2012). ${ }^{18} \mathrm{~F}$-Fluro-deoxy-glucose is a widely used biomarker of synaptic activity that can indicate the topography of neurodegeneration using Positron Emission Tomography ( ${ }^{18}$ F-FDG PET) (Didic et al., 2015; Koric et al., 2016; Titov et al., 2015; Varrone et al., 2012). ${ }^{18}$ F-FDG-PET also provides an opportunity to study functional synaptic changes in severely deaf patients, not only before, but also after CI, without magnetic limitations or contraindications (Strelnikov et al., 2015). However, only two pilot studies, in small sets of adults with hearing loss, have so far assessed cerebral metabolism using PET (Deggouj et al., 1995; Lee et al., 2003).

Beyond the identification of metabolic dysfunction within individual brain regions, the analysis of functional connectivity leads to a better understanding of neural plasticity on the 
network scale. Hence, PET can be used to study metabolic connectivity by Inter-Regional Correlation Analysis (IRCA) (Lee et al., 2008), these resting-state networks being closely related to those derived from fMRI studies (Di et al., 2012; Savio et al., 2017; Yakushev et al., 2013). Although the spatial resolution of PET is worse than that of fMRI, PET targets glucose consumption, which reflects synaptic activity, and is therefore particularly well suited to assess neural plasticity. Furthermore, glucose consumption has the advantage of preceding the BOLD (Blood Oxygen Level Dependent) signal and can therefore detect early changes in neuronal function (Magistretti and Pellerin, 1999). The assessment of functional connectivity using ${ }^{18} \mathrm{~F}-\mathrm{FDG}$ PET could thus characterize changes of the connectome in patients with impaired hearing at the large neural network scale. Thus, the metabolic connectome studied here refers to the same concept as functional connectome or functional connectivity. To our knowledge, there is currently no PET study on metabolic connectivity in adults with lateonset hearing loss.

The aim of this study was to characterize cerebral metabolic PET changes in elderly patients fulfilling criteria of $\mathrm{CI}$ for hearing loss and investigate neural plasticity through the assessment of functional connectivity. 


\section{Materials and Methods}

\subsection{Subjects}

Thirty-two adults with post-lingual hearing loss were referred from August 2013 to July 2016 to "La Timone" University Hospital at Marseille to perform a neurocognitive assessment before cochlear implantation (CI) in order to rule out a neurodegenerative condition. These patients fulfilled the criterion for CI as defined in France, i.e. speech perception below $50 \%$ at $60 \mathrm{~dB}$ without lip-reading (HAS santé, 2012). Neurocognitive assessment involved the MiniMental State Examination (MMSE) (Folstein et al., 1975) and the Frontal Assessment Battery (FAB) (Dubois et al., 2000). Brain MRI and ${ }^{18}$ F-FDG-PET were also performed in these patients. Sufficient and detailed explanations for the procedure, risk, and purpose or benefit of the study were given to the patients by clinicians. All patients participated with informed written consent in accordance with the Declaration of Helsinki (number of international review board of local ethical committee: 00003888).

Five patients were excluded from further analysis because of neurological or psychiatric comorbidity. One patient was reported to have suffered from epilepsy since his childhood, and from concussion that caused a focal fronto-temporal lesion with right hemiplegia at the age of 46. The second patient had suffered from three consecutive strokes with residual right hemiplegia. The third patient was suffering from psychosis since the age of 23 and was under antipsychotic medication. Two additional patients were excluded because of a left temporal arachnoid cyst detected on CT-scan, which could interfere with the PET analysis.

Healthy subjects from a local normal ${ }^{18} \mathrm{~F}-\mathrm{FDG}$ PET database, matched to patients for age, gender, and level of education (Clinical Trials Ref: NCT00987090), were also included. These controls were free of neurological and psychiatric disease with a normal brain MRI. None of these control subjects had a medical history of hearing loss or complained about their 


\section{$2.2^{18}$ F-FDG PET Acquisition and Analysis}

${ }^{18} \mathrm{~F}-\mathrm{FDG}$ PET was performed under the same conditions for all patients and healthy subjects, using an integrated PET/CT camera (Discovery ST, GE Healthcare, Waukesha, WI) with an axial resolution of $6.2 \mathrm{~mm}$ allowing 47 contiguous transverse sections of the brain of $3.27 \mathrm{~mm}$ thickness. ${ }^{18} \mathrm{~F}-\mathrm{FDG}(150 \mathrm{MBq})$ was injected intravenously while the subjects were awake, at resting state, with eyes closed in a quiet environment. Image acquisition started $30 \mathrm{~min}$ after injection and ended $15 \mathrm{~min}$ later. Images were reconstructed using the ordered subsets expectation maximization algorithm with 5 iterations and 32 subsets, and corrected for attenuation using a CT transmission scan.

Whole-brain statistical analysis was performed at voxel-level using SPM8 software (Wellcome Department of Cognitive Neurology, University College, London, UK) to compare patients with hearing loss and controls using ANOVA (Analysis of Variance). PET images were spatially normalized onto an adaptive template derived from PET images of controls. The images were then smoothed with a Gaussian filter $(8 \mathrm{~mm}$ full-width at halfmaximum) to blur individual variations in gyral anatomy and to increase the signal-to-noise ratio. To build the adaptive template, the PET scans of the 27 control subjects were normalized to the standard PET template, using the algorithm provided with SPM. Then, the template was built by averaging these normalized images and subsequently applying a smoothing Gaussian filter $(\mathrm{FWHM}=8 \times 8 \times 8 \mathrm{~mm})$ (Gispert et al., 2003). The dimensions of the resulting voxels were $2 \times 2 \times 2 \mathrm{~mm}$. Between groups SPM (T) maps were obtained at a threshold (voxel-level significance) of $\mathrm{p}<0.005$, uncorrected at voxel-level, but with a 
correction for cluster volume, using expected voxels per cluster provided by SPM, to avoid type II errors, as recommended (Lieberman and Cunningham, 2009), with age, gender and level of education as nuisance covariates. An additional analysis with small volume correction (SVC) was applied within the most significant voxel of the left auditory area. Proportional scaling was applied, giving the same global value to each PET acquisition, to correct for individual variations in global cerebral metabolism. The anatomical localization of the most significant voxels was then identified using the MNI (Montreal National Institute) atlas. Mean values of Cerebral Metabolic Rate of Glucose (CMRGlc) were extracted at the individual level for each significant cluster. To evaluate metabolic connectivity from the previously identified metabolic cluster in the intergroup comparison, IRCA was performed according to the procedure validated by Lee et al. (Lee et al., 2008). Briefly, mean values of CMRGlc were used as interacted covariates for the comparison between connectivity in patients and controls. Nuisance covariates and threshold were the same as previously detailed for groups SPM (T) maps comparisons.

A Region of Interest (ROI) analysis of the left associative auditory cortex was also performed by extracting CMRGlc of cluster identified after analysis by small volume correction. Moreover, an asymmetry index was calculated ((left auditory CMRGlc-right auditory CMRGlc)/(left auditory CMRGlc+right auditory CMRGlc).

\subsection{Statistical analysis}

Quantitative variables (age, level of education, deafness duration, MMSE and FAB scores) are expressed as means \pm standard deviations, and categorical variables (gender) as percentages. T-tests were performed for mean comparison between two quantitative variables with normal distribution and Chi-square tests for comparison between two categorical 
variables. Spearman coefficients were used to determine correlations between CMRGlc of identified areas and test scores. A $p<0.05$ was determined as significant. Statistical analysis on SPM is mentioned above. 


\subsection{Patients and controls}

Of the twenty-seven patients with post-lingual hearing loss who only used spoken language, as well as lip-reading, included into the present analysis (mean age $72.9 \pm 5.8$ years, 15 women, AFPA educational score, 4.2 \pm 1.2 ; French assessment of educational level, https://www.afpa.fr), the duration of a speech perception score at $50 \%$ or below with hearing aids at $60 \mathrm{~dB}$ and without lip-reading was $7.0 \pm 3.1$ years. The duration of hearing aid use was $18 \pm 11$ years. The etiology of hearing loss was most frequently unknown (52\%) (Table 1). Twenty-seven healthy subjects were matched to patients for age ( $72.3 \pm 7.6$ years), gender ( 15 women), and level of education (AFPA educational score: $3.7 \pm 1.2 ; p>0.17$ ). Cognitive performance of patients on the MMSE (Folstein et al., 1975) and the FAB (Dubois et al., 2000) was below that of healthy subjects $(\mathrm{p}<0.05$; Table 2$)$.

\subsection{Metabolic PET findings}

In comparison to healthy controls, patients showed decreased metabolism within the right superior temporal gyrus (BA21 and 22), part of the associative auditory cortex $(\mathrm{p}<0.005$, uncorrected, $\mathrm{k}>213$; Figure 1). For the left associative auditory cortex, no supra-threshold cluster was initially found when a p-value of 0.005 corrected for the cluster volume was applied. However, an additional analysis with SVC (sphere of $4160 \mathrm{~mm} 3$, which is an equivalent volume of the cluster found in right area with center coordinates at $-52 ;-22 ; 0$, i.e. the most significant voxel of the left auditory area) secondarily identified a significant cluster after SVC for this same voxel threshold (p-cluster $=0.037$, FWE-corrected $)$. 
Mean values of CMRGlc of previously identified areas were extracted for each individual patient. No association was found between duration of deafness and metabolism of any of these areas, including the right superior temporal gyrus $(\mathrm{p}>0.20)$. However, metabolism of both the right superior temporal and left inferior parietal gyri was positively correlated with performance on cognitive tests. In detail, decreased metabolism of the right superior temporal gyrus was correlated with lower MMSE and FAB scores (respective correlation coefficients of 0.48 and $0.54, p<0.05)$. Concerning regions with increased metabolism in comparison to healthy subjects, increased metabolism of the left inferior parietal gyrus was positively correlated with better performance on the FAB (correlation coefficients of $0.51, \mathrm{p}<0.05$ ).

Otherwise, decreased metabolism of the left associative auditory cortex was correlated with lower performance on FAB (correlation coefficient of $0.70, \mathrm{p}=0.01$ ). Moreover, right prevalent asymmetry was associated with better performance on MMSE score (correlation coefficient of $-0.50, \mathrm{p}=0.02)$.

In a second step, we studied metabolic connectivity of the right temporal gyrus (BA21 and 22), part of the associative auditory cortex, which was found to be the only area with decreased metabolism. Figure 3 illustrates the direct comparison of right BA21-22 connectivity between patients with hearing loss and controls. Patients showed increased 
connectivity of this region with the right superior and middle temporal gyri (BA21, 22 and 42), right precentral frontal and postcentral parietal gyri (BA4, 6 and 3), right inferior parietal gyrus (BA40), the cingulum (BA23, 24 and 32), as well as with the right and the left striatum $(\mathrm{P}<0.005$, uncorrected, $\mathrm{k}>136)$. Detailed coordinates of all these findings are available in Table 3. No reduced connectivity was observed in patients in comparison to controls.

\section{Discussion}

The main finding of the present study in elderly patients with severe to profound hearing loss is that decreased metabolism within the right associative auditory cortex (BA21-22) is combined with increased metabolism in prefrontal, pre- and post-central areas, the cingulum as well as the left inferior parietal gyrus and integrated within a network of increased metabolic connectivity that includes pre- and post-central areas, the cingulum, the right inferior parietal gyrus, as well as the striatum on both sides. Moreover, metabolism of the right superior temporal and left inferior parietal gyri was positively correlated with performance on cognitive tests. Decreased metabolism was also found for the left associative auditory cortex after SVC. These findings contribute to the identification of neural plasticity and changes of functional connectivity in elderly patients with severe hearing loss.

4.1 Decreased cerebral metabolism in elderly patients with hearing loss: a specific metabolic pattern?

Decreased metabolism within the right associative auditory cortex is in line with previous ${ }^{18} \mathrm{~F}$ FDG PET pilot studies in two adults with late-onset hearing loss (one man aged 61 and one 
woman aged 47) (Deggouj et al., 1995) and in 9 late-onset deaf younger adults with severe

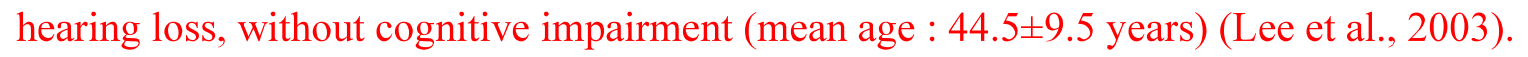

However, unlike the findings of the present study, Lee et al. reported an additional decrease of cerebral glucose metabolism in superior temporal cortices of both hemispheres, as well as the anterior cingulate gyri and in the right parahippocampal gyrus, with a similar or more restricted level of significance then that used in the present study, but with a slightly different target population (Lee et al., 2003). A decrease of glucose metabolism in the right superior temporal gyrus might be expected due to the role of this region in the evaluation of sentence and context processing (Vigneau et al., 2011). Indeed, right hemispheric activity allows one to move beyond the literal meaning of a word, a task necessary to appropriately interpret an utterance in its context (Lindell, 2006).

The relationship between cognitive dysfunction and hearing loss remains incompletely understood. An association of hearing loss with lower MMSE scores was reported in a study that included more than 300 participants ( $>55$ years old) (Lin et al., 2011a). Here, we found that right prevalent asymmetry was associated with better performance on the MMSE, with a positive correlation of metabolism in the right associative auditory cortex with performance on neuropsychological tasks (MMSE and FAB). Indeed, a PET study involving healthy controls showed higher metabolism in the right associative auditory cortex in comparison to the left (Geven et al., 2014). A right prevalent asymmetry within the associative auditory cortex might therefore be associated with the auditory status of healthy subjects and thus a better MMSE. This association with neuropsychological tests was also found after SVC for the left associative auditory cortex with FAB. Although poor verbal communication associated with hearing loss may confound cognitive testing (Gordon-Salant, 2005), the patients in the present study clearly gave the impression of having understood the instructions that they were given (including the repetition of the sentence of the MMSE where they failed 
because of difficulty hearing given the complexity of the sentence). While a relationship between metabolism within the left associative auditory cortex with performance on language based cognitive scores could have been expected, as auditory comprehension is likely to impact speech processing of the left hemisphere, the present finding of an association with metabolism in the right auditory cortex could be related to a compensatory involvement of the right hemisphere (Lazard et al., 2014).

Finally, the pattern of hypometabolism in elderly patients with hearing loss is also distinct from that usually found in common cortical neurodegenerative diseases (Mosconi et al., 2008). Although the possibility that sensory deprivation directly triggers a neurodegenerative cascade cannot be formally ruled out, a more likely explanation is that hearing loss may cause cognitive decline through social isolation or cognitive load, or a combination of these mechanisms (Strawbridge et al., 2000; Lin et al., 2011a; Amieva et al., 2015). Hence, cognitive load induced by hearing loss is thought to reduce resources being available for other cognitive tasks as suggested by the "resource capacity model" (Kahneman, 1973) and thereby affect cognitive function as previously reported in patients with impaired hearing (Lin et al., 2011a). In this context, compensatory resource-allocation for sensory deprivation through reorganization of cerebral networks may be critical but not sufficient to maintain cognitive function.

\subsection{Increased cerebral metabolism and changes of connectivity in elderly patients with hearing loss: towards functional reorganization?}

A network of areas with increased metabolism and changes of connectivity was found in patients in comparison to controls. This is likely to result from a compensatory effect, as increased metabolism in the left inferior parietal gyrus was correlated with better performance 
on the FAB. Plastic changes in the cerebral cortex have been largely demonstrated in animal studies (Irvine and Rajan, 1996; Rajan et al., 1993; Çakır et al., 2015; Suh et al., 2016). In the auditory system, experience-dependent alterations in receptive field properties were investigated by partial destruction of the cochlea, leading to reorganization within the primary auditory cortex (Irvine and Rajan, 1996; Rajan et al., 1993). There is also evidence for somatosensory cross-modal plasticity in post-lingually deaf adults (Doucet et al., 2006; Sandmann et al., 2012). In this line, Kang et al. reported changes in functional PET connectivity with the auditory cortex in 91 deaf children and 20 young adults (Kang et al., 2003). Functional connectivity was mostly loco-regional, involving the temporal cortex and was more increased in deaf children than in deaf or normal hearing adults (Kang et al., 2003). In addition, distant activations from the primary auditory cortex were observed in adults with hearing loss, involving the left inferior frontal gyrus, in a rhyme-task activation fMRI study (MacSweeney et al., 2009). In this study, the authors showed a greater activation in the deaf and dyslexic groups than in the hearing non-dyslexic group across a large portion of the left inferior frontal gyrus, suggestive of compensatory effects.

In the present study, increased metabolic changes and increased connectivity with the auditory cortex were mainly found in prefrontal areas, the cingulum and striatum bilaterally, regions involved in executive and limbic functions (Hanlon et al., 2013; Roxo et al., 2011), reinforcing the hypothesis of plasticity. This is in line with an fMRI task activation study that showed increased activation of frontal cortices during degraded listening situations in adults with or without hearing loss (Peelle et al., 2011), suggesting that frontal cortices improve sensory perception via top-down modulatory control. Indeed, in the case of hearing-loss, frontal areas are probably recruited because of their implication in selective attention (Peelle et al., 2011), as observed in visual deprivation (Frezzotti et al., 2014). The findings are also coherent with increased activation in frontal cortical areas observed using auditory evoked 


\subsection{Compensation: both cross-modal plasticity and top-down modulatory control?}

It is noteworthy that the finding of increased metabolism within inferior parietal gyri could be related to compensation through proprioceptive processing, suggesting cross-modal recruitment (Gick and Derrick, 2009). Moreover, pre- and post-central areas, regions of the sensitive-motor cortex, were also found to have increased metabolism or increased connectivity with associative auditory cortex, such as pre- and post-central gyri (BA2, 3, 4, 6 and 7). In this case, cross-modal recruitment by the somatosensory system may be related to: i) the close proximity of auditory and somatosensory cortices (Allman et al., 2009), ii) the overlap of the auditory and somatosensory pathways sub-cortically (Dehmel et al., 2008), iii) increased reliance on vibrotactile inputs known to play a role in auditory speech perception and production (Gick and Derrick, 2009), or iv) increased reliance on lip-reading, and on a parieto-premotor "mirror system" involved in both the production and observation of mouthrelated actions (Buccino et al., 2004, 2001). In this line, a cross-modal model with visual function has also been described previously in deaf patients (Strelnikov et al., 2011; Barone et al., 2016). Such cross-modal influence is observed in speech and in non-speech situations, such as face-voice interactions, which are crucial to social interaction. The clear visual impact 


\section{4 Limitations of the present study}

The present study has several limitations. Although the pattern of decreased metabolism differed from that of patients with neurodegenerative diseases, we cannot rule out that metabolic changes on PET related to neurodegenerative disorders in some patients might have influenced these findings. A more precise assessment of neurocognitive function should be performed in these patients and correlated with PET findings. Secondly, in order to increase sensitivity, a threshold of $\mathrm{p}<0.005$ corrected for cluster volume was chosen for statistical significance in SPM, leading to exposing to type I error. However, this threshold has been widely used in quantitative analysis studies, including the previously described PET examination of glucose metabolism in deaf adults (Lee et al., 2003). Finally, a post-CIevaluation is needed to assess functional reorganization after cochlear implantation, in order to address the potential reversibility of compensatory mechanisms. In this line, the selection 
of PET imaging to study the changes of the connectome makes sense given the absence of magnetic interference caused by cochlear implantation.

\section{Conclusions}

This study shows that hearing loss in elderly patients, as assessed by cerebral ${ }^{18} \mathrm{~F}$-FDG-PET, leads to a specific metabolic pattern of decreased of metabolism in the associative auditory cortex, and is associated with functional reorganization of the connectome. In addition, associated multimodal increased metabolism and connectivity, correlated with better performance on cognitive tasks, indicates functional reorganization likely to be related to compensatory mechanisms. The topography of increased metabolism and the changes of connectivity suggest that compensation may not only involve cross-modal plasticity but also top-down modulatory control. These findings add to the evidence that neuroplasticity continues through age. Future studies with extensive neuropsychological assessment need to address how changes of cognition are related to functional reorganization, and how CI can contribute to reestablish the connectome and therefore contribute to successful aging.

\section{Funding:}

This study has been carried out in the framework of DHU-Imaging thanks to the support of the A*MIDEX project ( ${ }^{\circ}$ ANR-11-IDEX-0001-02) funded by the «Investissements d'Avenir » French Government program, managed by the French National Research Agency (ANR). 


\section{Conflict of Interest:}

The authors declare that they have no conflict of interest.

\section{Authors role:}

All authors have participated either to: 1) conception and design or analysis and interpretation of data, or both (AV, SR, RMC, MD, EG); 2) drafting of the manuscript or revising it critically for important intellectual content (AV, SR, MD, EG) or 3) final approval of the manuscript submitted (OF, MC, EG). 


\section{References}

Allman, B.L., Keniston, L.P., Meredith, M.A., 2009. Adult deafness induces somatosensory conversion of ferret auditory cortex. Proc. Natl. Acad. Sci. U. S. A. 106, 5925-5930. doi:10.1073/pnas.0809483106

Amieva, H., Ouvrard, C., Giulioli, C., Meillon, C., Rullier, L., Dartigues, J.-F., 2015. Self-Reported Hearing Loss, Hearing Aids, and Cognitive Decline in Elderly Adults: A 25-Year Study. J. Am. Geriatr. Soc. 63, 2099-2104. doi:10.1111/jgs.13649

Barone, P., Chambaudie, L., Strelnikov, K., Fraysse, B., Marx, M., Belin, P., Deguine, O., 2016. Crossmodal interactions during non-linguistic auditory processing in cochlear-implanted deaf patients. Cortex J. Devoted Study Nerv. Syst. Behav. 83, 259-270. doi:10.1016/j.cortex.2016.08.005

Buccino, G., Binkofski, F., Fink, G.R., Fadiga, L., Fogassi, L., Gallese, V., Seitz, R.J., Zilles, K., Rizzolatti, G., Freund, H.J., 2001. Action observation activates premotor and parietal areas in a somatotopic manner: an fMRI study. Eur. J. Neurosci. 13, 400-404.

Buccino, G., Lui, F., Canessa, N., Patteri, I., Lagravinese, G., Benuzzi, F., Porro, C.A., Rizzolatti, G., 2004. Neural circuits involved in the recognition of actions performed by nonconspecifics: an FMRI study. J. Cogn. Neurosci. 16, 114-126. doi:10.1162/089892904322755601

Çakır, A., Ecevit, M.C., Bal, R., Gürkan, S., Alpay, H.C., Şerbetçioğlu, M.B., 2015. Assessment of Synaptic Plasticity via Long-Term Potentiation in Young Mice on the Day after Acoustic Trauma: Implications for Tinnitus. J. Int. Adv. Otol. 11, 196-201. doi:10.5152/iao.2015.1047

Campbell, J., Sharma, A., 2013. Compensatory changes in cortical resource allocation in adults with hearing loss. Front. Syst. Neurosci. 7. doi:10.3389/fnsys.2013.00071

Cason, N., Schön, D., 2012. Rhythmic priming enhances the phonological processing of speech. Neuropsychologia 50, 2652-2658. doi:10.1016/j.neuropsychologia.2012.07.018 
Cousins, K.A.Q., Dar, H., Wingfield, A., Miller, P., 2014. Acoustic masking disrupts time-dependent mechanisms of memory encoding in word-list recall. Mem. Cognit. 42, 622-638. doi:10.3758/s13421-013-0377-7

Cruickshanks, K.J., Wiley, T.L., Tweed, T.S., Klein, B.E.K., Klein, R., Mares-Perlman, J.A., Nondahl, D.M., 1998. Prevalence of Hearing Loss in Older Adults in Beaver Dam, Wisconsin: The Epidemiology of Hearing Loss Study. Am. J. Epidemiol. 148, 879-886.

doi:10.1093/oxfordjournals.aje.a009713

Deggouj, N., Devolder, A., Catalan, M., Melin, J., Michel, C., Gersdorff, M., Veraart, C., 1995. Positron emission tomography in deaf patients at rest. Adv. Otorhinolaryngol. 50, 31-37.

Dehmel, S., Cui, Y.L., Shore, S.E., 2008. Cross-modal interactions of auditory and somatic inputs in the brainstem and midbrain and their imbalance in tinnitus and deafness. Am. J. Audiol. 17, S193-209. doi:10.1044/1059-0889(2008/07-0045)

Di, X., Biswal, B.B., Alzheimer's Disease Neuroimaging Initiative, 2012. Metabolic brain covariant networks as revealed by FDG-PET with reference to resting-state fMRI networks. Brain Connect. 2, 275-283. doi:10.1089/brain.2012.0086

Didic, M., Felician, O., Gour, N., Bernard, R., Pécheux, C., Mundler, O., Ceccaldi, M., Guedj, E., 2015. Rhinal hypometabolism on FDG PET in healthy APO-E4 carriers: impact on memory function and metabolic networks. Eur. J. Nucl. Med. Mol. Imaging 42, 1512-1521. doi:10.1007/s00259-015-3057-y

Doucet, M.E., Bergeron, F., Lassonde, M., Ferron, P., Lepore, F., 2006. Cross-modal reorganization and speech perception in cochlear implant users. Brain J. Neurol. 129, 3376-3383. doi:10.1093/brain/awl264

Dubois, B., Slachevsky, A., Litvan, I., Pillon, B., 2000. The FAB: a Frontal Assessment Battery at bedside. Neurology 55, 1621-1626.

Folstein, M.F., Folstein, S.E., McHugh, P.R., 1975. "Mini-mental state". A practical method for grading the cognitive state of patients for the clinician. J. Psychiatr. Res. 12, 189-198. 
Frezzotti, P., Giorgio, A., Motolese, I., De Leucio, A., lester, M., Motolese, E., Federico, A., De Stefano, N., 2014. Structural and Functional Brain Changes beyond Visual System in Patients with Advanced Glaucoma. PLoS ONE 9, e105931. doi:10.1371/journal.pone.0105931

Gates, G.A., Anderson, M.L., McCurry, S.M., Feeney, M.P., Larson, E.B., 2011. Central Auditory Dysfunction as a Harbinger of Alzheimer Dementia. Arch. Otolaryngol. Neck Surg. 137, 390. doi:10.1001/archoto.2011.28

Geven, L.I., de Kleine, E., Willemsen, A.T.M., van Dijk, P., 2014. Asymmetry in primary auditory cortex activity in tinnitus patients and controls. Neuroscience 256, 117-125. doi:10.1016/j.neuroscience.2013.10.015

Gick, B., Derrick, D., 2009. Aero-tactile integration in speech perception. Nature 462, 502-504. doi:10.1038/nature08572

Gispert, J.D., Pascau, J., Reig, S., Martínez-Lázaro, R., Molina, V., García-Barreno, P., Desco, M., 2003. Influence of the normalization template on the outcome of statistical parametric mapping of PET scans. Neurolmage 19, 601-612.

Glick, H., Sharma, A., 2017. Cross-modal plasticity in developmental and age-related hearing loss: Clinical implications. Hear. Res. 343, 191-201. doi:10.1016/j.heares.2016.08.012

Gordon-Salant, S., 2005. Hearing loss and aging: new research findings and clinical implications. J. Rehabil. Res. Dev. 42, 9-24.

Hanlon, C.A., Canterberry, M., Taylor, J.J., DeVries, W., Li, X., Brown, T.R., George, M.S., 2013. Probing the Frontostriatal Loops Involved in Executive and Limbic Processing via Interleaved TMS and Functional MRI at Two Prefrontal Locations: A Pilot Study. PLoS ONE 8, e67917. doi:10.1371/journal.pone.0067917

HAS santé, 2012. fiche_bon_usage_implants_cochleaires.

Irvine, D.R., Rajan, R., 1996. Injury- and use-related plasticity in the primary sensory cortex of adult mammals: possible relationship to perceptual learning. Clin. Exp. Pharmacol. Physiol. 23, 939-947. 
Kahneman, D., 1973. Attention and effort. Englewood Cliffs.

Kang, E., Lee, D.., Lee, J., Kang, H., Hwang, C.., Oh, S.., Kim, C.., Chung, J.-K., Lee, M.., Jang, M.., Lee, Y.., Morosan, P., Zilles, K., 2003. Developmental hemispheric asymmetry of interregional metabolic correlation of the auditory cortex in deaf subjects. Neurolmage 19, 777-783. doi:10.1016/S1053-8119(03)00118-6

Koric, L., Guedj, E., Habert, M.O., Semah, F., Branger, P., Payoux, P., Le Jeune, F., CMMR study group, 2016. Molecular imaging in the diagnosis of Alzheimer's disease and related disorders. Rev. Neurol. (Paris) 172, 725-734. doi:10.1016/j.neurol.2016.10.009

Kotz, S.A., Schwartze, M., 2010. Cortical speech processing unplugged: a timely subcortico-cortical framework. Trends Cogn. Sci. 14, 392-399. doi:10.1016/j.tics.2010.06.005

Kral, A., Kronenberger, W.G., Pisoni, D.B., O'Donoghue, G.M., 2016. Neurocognitive factors in sensory restoration of early deafness: a connectome model. Lancet Neurol. 15, 610-621. doi:10.1016/S1474-4422(16)00034-X

Lazard, D.S., Innes-Brown, H., Barone, P., 2014. Adaptation of the communicative brain to postlingual deafness. Evidence from functional imaging. Hear. Res. 307, 136-143. doi:10.1016/j.heares.2013.08.006

Lee, D.S., Kang, H., Kim, H., Park, H., Oh, J.S., Lee, J.S., Lee, M.C., 2008. Metabolic connectivity by interregional correlation analysis using statistical parametric mapping (SPM) and FDG brain PET; methodological development and patterns of metabolic connectivity in adults. Eur. J. Nucl. Med. Mol. Imaging 35, 1681-1691. doi:10.1007/s00259-008-0808-z

Lee, J.S., Lee, D.S., Oh, S.H., Kim, C.S., Kim, J.-W., Hwang, C.H., Koo, J., Kang, E., Chung, J.-K., Lee, M.C., 2003. PET evidence of neuroplasticity in adult auditory cortex of postlingual deafness. J. Nucl. Med. Off. Publ. Soc. Nucl. Med. 44, 1435-1439.

Lesicko, A.M.H., Llano, D.A., 2017. Impact of peripheral hearing loss on top-down auditory processing. Hear. Res. 343, 4-13. doi:10.1016/j.heares.2016.05.018 
Lethbridge-Cejku, M., Schiller, J.S., Bernadel, L., 2004. Summary health statistics for U.S. adults: National Health Interview Survey, 2002. Vital Health Stat. 10. 1-151.

Lieberman, M.D., Cunningham, W.A., 2009. Type I and Type Il error concerns in fMRI research: rebalancing the scale. Soc. Cogn. Affect. Neurosci. 4, 423-428. doi:10.1093/scan/nsp052

Lin, F.R., Ferrucci, L., Metter, E.J., An, Y., Zonderman, A.B., Resnick, S.M., 2011a. Hearing loss and cognition in the Baltimore Longitudinal Study of Aging. Neuropsychology 25, 763-770. doi:10.1037/a0024238

Lin, F.R., Metter, E.J., O'Brien, R.J., Resnick, S.M., Zonderman, A.B., Ferrucci, L., 2011b. Hearing Loss and Incident Dementia. Arch. Neurol. 68. doi:10.1001/archneurol.2010.362

Lindell, A.K., 2006. In your right mind: right hemisphere contributions to language processing and production. Neuropsychol. Rev. 16, 131-148. doi:10.1007/s11065-006-9011-9

MacSweeney, M., Brammer, M.J., Waters, D., Goswami, U., 2009. Enhanced activation of the left inferior frontal gyrus in deaf and dyslexic adults during rhyming. Brain J. Neurol. 132, 19281940. doi:10.1093/brain/awp129

Magistretti, P.J., Pellerin, L., 1999. Cellular mechanisms of brain energy metabolism and their relevance to functional brain imaging. Philos. Trans. R. Soc. Lond. B. Biol. Sci. 354, 11551163. doi:10.1098/rstb.1999.0471

McCoy, S.L., Tun, P.A., Cox, L.C., Colangelo, M., Stewart, R.A., Wingfield, A., 2005. Hearing loss and perceptual effort: Downstream effects on older adults' memory for speech. Q. J. Exp. Psychol. Sect. A 58, 22-33. doi:10.1080/02724980443000151

Mosconi, L., Tsui, W.H., Herholz, K., Pupi, A., Drzezga, A., Lucignani, G., Reiman, E.M., Holthoff, V., Kalbe, E., Sorbi, S., Diehl-Schmid, J., Perneczky, R., Clerici, F., Caselli, R., Beuthien-Baumann, B., Kurz, A., Minoshima, S., de Leon, M.J., 2008. Multicenter standardized 18F-FDG PET diagnosis of mild cognitive impairment, Alzheimer's disease, and other dementias. J. Nucl. Med. Off. Publ. Soc. Nucl. Med. 49, 390-398. doi:10.2967/jnumed.107.045385 
Peelle, J.E., Troiani, V., Grossman, M., Wingfield, A., 2011. Hearing loss in older adults affects neural systems supporting speech comprehension. J. Neurosci. Off. J. Soc. Neurosci. 31, 1263812643. doi:10.1523/JNEUROSCI.2559-11.2011

Rajan, R., Irvine, D.R., Wise, L.Z., Heil, P., 1993. Effect of unilateral partial cochlear lesions in adult cats on the representation of lesioned and unlesioned cochleas in primary auditory cortex. J. Comp. Neurol. 338, 17-49. doi:10.1002/cne.903380104

Ramos-Macías, Á., Falcón González, J.C., Borkoski-Barreiro, S.A., Ramos de Miguel, Á., Batista, D.S., Pérez Plasencia, D., 2016. Health-Related Quality of Life in Adult Cochlear Implant Users: A Descriptive Observational Study. Audiol. Neurootol. 21 Suppl 1, 36-42. doi:10.1159/000448353

Roxo, M.R., Franceschini, P.R., Zubaran, C., Kleber, F.D., Sander, J.W., 2011. The Limbic System Conception and Its Historical Evolution. Sci. World J. 11, 2427-2440. doi:10.1100/2011/157150

Sandmann, P., Dillier, N., Eichele, T., Meyer, M., Kegel, A., Pascual-Marqui, R.D., Marcar, V.L., Jäncke, L., Debener, S., 2012. Visual activation of auditory cortex reflects maladaptive plasticity in cochlear implant users. Brain J. Neurol. 135, 555-568. doi:10.1093/brain/awr329

Savio, A., Fünger, S., Tahmasian, M., Rachakonda, S., Manoliu, A., Sorg, C., Grimmer, T., Calhoun, V., Drzezga, A., Riedl, V., Yakushev, I., 2017. Resting state networks as simultaneously measured with fMRI and PET. J. Nucl. Med. Off. Publ. Soc. Nucl. Med. doi:10.2967/jnumed.116.185835

Sporns, O., Tononi, G., Kötter, R., 2005. The human connectome: A structural description of the human brain. PLoS Comput. Biol. 1, e42. doi:10.1371/journal.pcbi.0010042

Strawbridge, W.J., Wallhagen, M.I., Shema, S.J., Kaplan, G.A., 2000. Negative consequences of hearing impairment in old age: a longitudinal analysis. The Gerontologist 40, 320-326.

Strelnikov, K., Marx, M., Lagleyre, S., Fraysse, B., Deguine, O., Barone, P., 2015. PET-imaging of brain plasticity after cochlear implantation. Hear. Res. 322, 180-187.

doi:10.1016/j.heares.2014.10.001 
Strelnikov, K., Rosito, M., Barone, P., 2011. Effect of audiovisual training on monaural spatial hearing in horizontal plane. PloS One 6, e18344. doi:10.1371/journal.pone.0018344

Suh, M.-W., Hyun, J., Lyu, A.-R., Kim, D.W., Park, S.J., Choi, J.W., Hur, G.M., Park, Y.-H., 2016. Compensation of Vestibular Function and Plasticity of Vestibular Nucleus after Unilateral Cochleostomy. Neural Plast. 2016, 7287180. doi:10.1155/2016/7287180

Titov, D., Diehl-Schmid, J., Shi, K., Perneczky, R., Zou, N., Grimmer, T., Li, J., Drzezga, A., Yakushev, I., 2015. Metabolic connectivity for differential diagnosis of dementing disorders. J. Cereb. Blood Flow Metab. doi:10.1177/0271678X15622465

Varrone, A., Dickson, J.C., Tossici-Bolt, L., Sera, T., Asenbaum, S., Booij, J., Kapucu, O.L., Kluge, A., Knudsen, G.M., Koulibaly, P.M., Nobili, F., Pagani, M., Sabri, O., Vander Borght, T., Van Laere, K., Tatsch, K., 2012. European multicentre database of healthy controls for [(123)I]FP-CIT SPECT (ENC-DAT): age-related effects, gender differences and evaluation of different methods of analysis. Eur. J. Nucl. Med. Mol. Imaging. doi:10.1007/s00259-012-2276-8

Vigneau, M., Beaucousin, V., Hervé, P.-Y., Jobard, G., Petit, L., Crivello, F., Mellet, E., Zago, L., Mazoyer, B., Tzourio-Mazoyer, N., 2011. What is right-hemisphere contribution to phonological, lexico-semantic, and sentence processing? Neurolmage 54, 577-593. doi:10.1016/j.neuroimage.2010.07.036

Wingfield, A., McCoy, S.L., Peelle, J.E., Tun, P.A., Cox, C.L., 2006. Effects of Adult Aging and Hearing Loss on Comprehension of Rapid Speech Varying in Syntactic Complexity. J. Am. Acad. Audiol. 17, 487-497. doi:10.3766/jaaa.17.7.4

Yakushev, I., Chételat, G., Fischer, F.U., Landeau, B., Bastin, C., Scheurich, A., Perrotin, A., Bahri, M.A., Drzezga, A., Eustache, F., Schreckenberger, M., Fellgiebel, A., Salmon, E., 2013. Metabolic and structural connectivity within the default mode network relates to working memory performance in young healthy adults. Neurolmage 79, 184-190.

doi:10.1016/j.neuroimage.2013.04.069 
16Platients Gender Age

Table 1: Patient data with gender, age at time of assessment, educational level, duration of speech perception scores $\leq \mathbf{5 0 \%}$ at $60 \mathrm{~dB}$ with hearing aids in years, experience with hearing aids in years and etiology of hearing loss.

\begin{tabular}{|c|c|c|c|c|c|}
\hline Gender & Age & $\begin{array}{c}\text { Educational } \\
\text { level } \\
\text { (in years) }\end{array}$ & $\begin{array}{c}\text { Speech perception } \\
\text { score } \leq 50 \% \text { at } 60 \\
\text { dB with hearing } \\
\text { aids } \\
\text { (in years) } \\
\end{array}$ & $\begin{array}{c}\text { Use of } \\
\text { Hearing aids } \\
\text { (in years) }\end{array}$ & Etiology of Hearing Loss (HL) \\
\hline $\mathrm{F}$ & 75 & 11 & 10 & 27 & unknown \\
\hline M & 75 & 18 & 7 & 10 & unknown \\
\hline $\mathrm{F}$ & 76 & 0 & 7 & 12 & unknown \\
\hline M & 79 & 5 & 7 & 17 & unknown \\
\hline $\mathrm{F}$ & 60 & 11 & 6 & 19 & genetic \\
\hline M & 73 & 14 & 10 & 19 & unknown \\
\hline $\mathrm{F}$ & 72 & 5 & 4 & 7 & unknown \\
\hline M & 66 & 9 & 8 & 26 & unknown \\
\hline $\mathrm{M}$ & 75 & 5 & 6 & 10 & $\begin{array}{l}\text { right cholesteatoma and left } \\
\text { sudden HL }\end{array}$ \\
\hline $\mathrm{F}$ & 67 & 9 & 9 & 27 & unknown \\
\hline $\mathrm{F}$ & 76 & 5 & 1 & 1 & labyrinthitis \\
\hline $\mathrm{F}$ & 73 & 12 & 7 & 12 & unknown \\
\hline $\mathrm{F}$ & 69 & 9 & 0.6 & 0 & bacterial meningitis \\
\hline $\mathrm{F}$ & 67 & 5 & 10 & 27 & otosclerosis \\
\hline $\mathrm{F}$ & 82 & 9 & 6 & 12 & unknown \\
\hline M & 76 & 17 & 7 & 26 & $\begin{array}{c}\text { progressive HL complicated by } \\
\text { sudden HL }\end{array}$ \\
\hline $\mathrm{F}$ & 64 & 11 & 9 & 40 & genetic HL \\
\hline M & 83 & 12 & 11 & 43 & unknown \\
\hline M & 66 & 2 & 9 & 15 & unknown \\
\hline $\mathrm{F}$ & 71 & 5 & 12 & 41 & otosclerosis \\
\hline M & 77 & 11 & 12 & 27 & unknown \\
\hline $\mathrm{F}$ & 70 & 8 & 4 & 8 & $\begin{array}{l}\text { unknown right HL and left } \\
\text { otosclerosis }\end{array}$ \\
\hline M & 73 & 12 & 7 & 12 & unknown \\
\hline $\mathrm{F}$ & 76 & 9 & 4 & 8 & otosclerosis \\
\hline M & 69 & 5 & 7 & 19 & Meniere's disease \\
\hline $\mathrm{F}$ & 84 & 5 & 1 & 1 & sudden HL \\
\hline $\mathrm{M}$ & 73 & 12 & 7 & 20 & sudden HL \\
\hline
\end{tabular}


Table 2. Characteristics of patients and healthy subjects

\begin{tabular}{lccc} 
& $\begin{array}{c}\text { Patients } \\
\mathbf{n = 2 7}\end{array}$ & $\begin{array}{c}\text { Healthy Subjects } \\
\mathbf{n = 2 7}\end{array}$ & p-value \\
\hline Age, years & $72.9(\mathrm{SD}=5.8)$ & $72.3(\mathrm{SD}=7.6)$ & 0.75 \\
Gender: female & $15(56 \%)^{*}$ & $15(56 \%)^{*}$ & 1 \\
Level of Education (AFPA score) & $4.2(\mathrm{SD}=1.2)$ & $3.7(\mathrm{SD}=1.2)$ & 0.17 \\
Duration of deafness, years & $7.0(\mathrm{SD}=4.1)$ & - & - \\
Psychometric assessment & & & \\
\multicolumn{1}{c}{ MMSE $(/ 30)$} & $26.3(\mathrm{SD}=3.1)$ & $28.9(\mathrm{SD}=1.1)$ & $0.01^{*}$ \\
\multicolumn{1}{c}{ FAB (/18) } & $16.3(\mathrm{SD}=1.6)$ & $17.3(\mathrm{SD}=1.1)$ & $0.04 *$ \\
\hline *: Percentage of categorical variables; MMSE: Mini Mental State Examination; FAB: Frontal \\
Assessment Battery.
\end{tabular}


Table 3. 18F-FDG-PET findings in patients with hearing loss in comparison with controls (Anatomical locations, spatial extents of significant Clusters, MNI coordinates, maximal z-Scores and height threshold of peak-voxel)

Peak Coordinates

Decreased metabolism in patients with hearing loss

in comparison to controls

Right superior temporal gyrus (BA 21 and 22)

322

58

$-12 \quad-2$

3.36

$<0.001$

Increased metabolism in patients with hearing loss

in comparison to controls

Left superior, middle, medial and precentral frontal gyri and cingulum (BA 4, 6, 9, 24, 31 and 32)

1934

$\begin{array}{lll}-14 & -10 & 74\end{array}$

3.89

$<0.001$

Right superior, middle, medial and precentral 2306

$\begin{array}{lll}12 & -12 \quad 60\end{array}$
frontal gyri, postcentral parietal gyrus and cingulum (BA 3, 4, 6, 8, 31 and 32)

Left postcentral and inferior parietal gyri (BA 2,7 and 40)

Increased connectivity with BA 21-22R

in patients with hearing loss in comparison to controls

Anterior cingulate (BA 24 and 32)

330

Right superior and middle temporal gyri (BA 21, 22 and 42)

$-14 \quad 20$

28

48

6


Right inferior parietal gyrus (BA 40)

235

$\begin{array}{lllll}42 & -40 & 44 & 3.42 & <0.001\end{array}$

Posterior cingulate (BA 23)

$\begin{array}{llllll}145 & -6 & -22 & 34 & 3.36 & <0.001\end{array}$

Right striatum

180

$24 \quad 16$

Left striatum

210

$-20$

$16 \quad 12$

$3.35<0.001$

Right precentral frontal and postcentral parietal gyri (BA 3, 4 and 6)

313

$60 \quad-4$

8

$3.28<0.001$

BA: Brodmann's Area. 
Figure 2. Anatomical localization of areas of increased of metabolism in patients with hearing loss in comparison to controls

Anatomical localization of areas of increased of metabolism in patients with hearing loss ( $p<0.005$, uncorrected, $\mathrm{k}>213$ ), in comparison to controls, projected onto sections of a standard SPM8 MRI template. In comparison to controls, patients with hearing loss showed increased metabolism in bilateral superior, middle, medial and pre-central frontal gyri, the cingulum, bilateral post-central parietal gyri, and the left inferior parietal gyrus. $B A$ : Brodmann's Area.

Figure 3. Anatomical localization of areas of increased right BA 21-22 connectivity in patients with hearing loss in comparison to controls

Anatomical localization of areas of increased right BA21-22 connectivity in patients with hearing loss ( $\mathrm{p}<0.005$, uncorrected, $\mathrm{k}>136)$ in comparison to controls projected onto 3D volume rendering (A) and standard SPM8 MRI template centered on the left caudate (B). 
Patients with hearing loss showed increased connectivity of BA21-22 on the right with the right superior and middle temporal gyri, the right precentral frontal and postcentral parietal gyri, the right inferior parietal gyrus, the cingulum, and the right and the left striatum. MRI: Magnetic Resonance Imaging; BA: Brodmann's Area. 